\title{
Was euthanasia dispute behind CMA-WMA split?
}

- Cite as: CMAJ 2018 November 19;190:E1369-70. doi: 10.1503/cmaj.109-5682

Posted on cmajnews.com on Oct. 30, 2018.

A long-running dispute over euthanasia between the Canadian Medical Association (CMA) and the World Medical Association (WMA) may have contributed to the CMA's decision to resign from the global medical body, according to some Canadian doctors.

The CMA walked out of the WMA's annual meeting on Oct. 6 , after it emerged that the WMA's new president, Dr. Leonid Eidelman, had plagiarized part of his inaugural speech from former CMA president
Dr. Chris Simpson. Eidelman apologized, but did not step down as the CMA demanded, so the CMA resigned from the organization.

But some doctors say that the plagiarism issue is not the whole story, and that the protracted disagreement between the CMA and WMA over euthanasia policy is the underlying reason for the resignation, a position apparently backed up by WMA leadership.

A letter from WMA secretary-general Dr. Otmer Kloiber to associate mem- bers of the WMA in Canada states that euthanasia has long been a sticking point between the two associations. "Over the past three years we have repeatedly received threats from members of the CMA delegation that the CMA might leave the WMA if the WMA's euthanasia policy was not changed," the letter states.

The WMA's official position on euthanasia is that it is unethical and must be condemned by the medical profession, despite

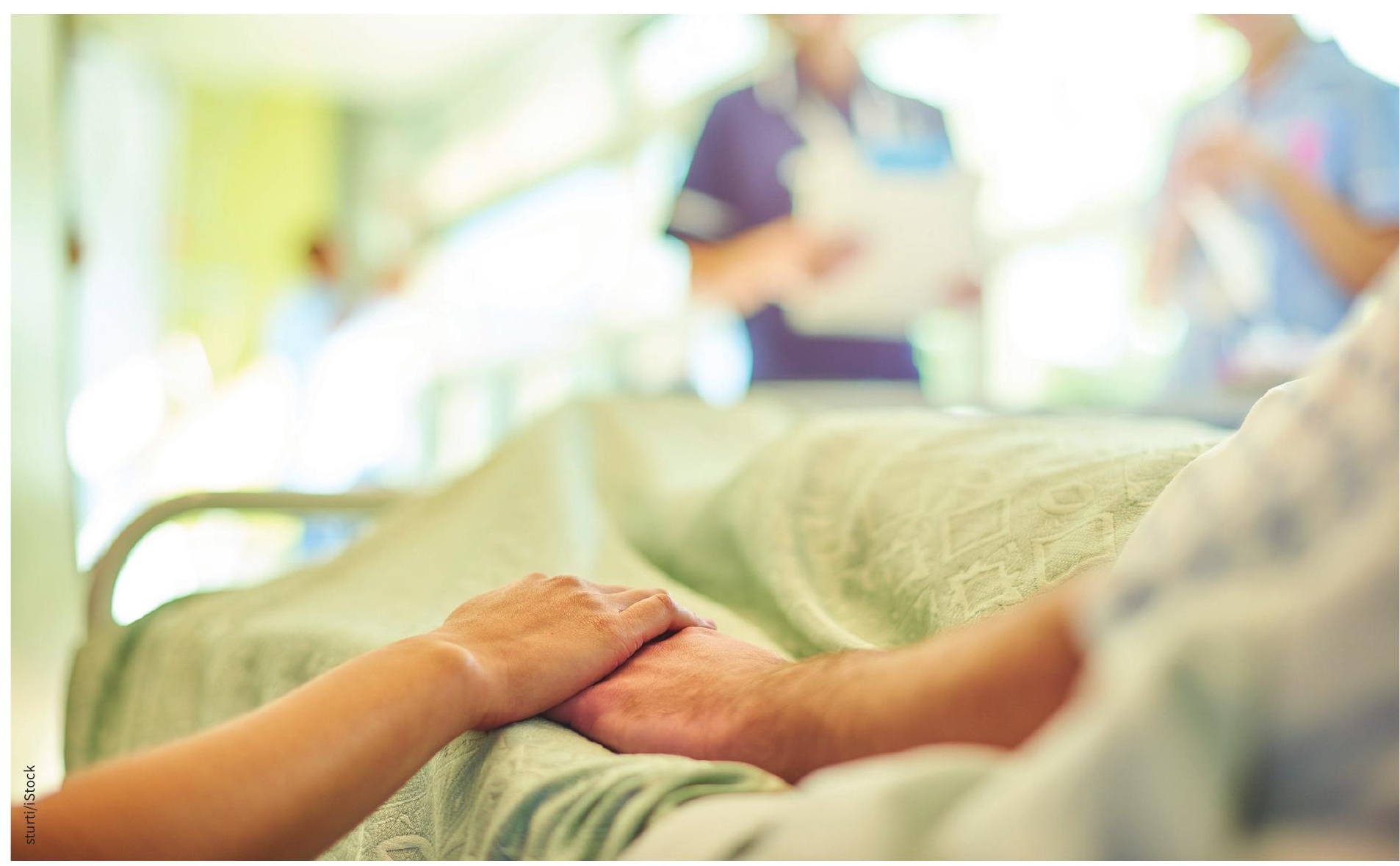

Euthanasia has been a point of contention between the CMA and WMA for years. 
it being legal in several of the association's member countries, including Canada. Kloiber said the WMA has always maintained good relations with its members who support euthanasia, such as the Netherlands, Belgium and Luxembourg, despite the difference of opinion. "There have been very critical discussions between the WMA and the Dutch, but we agreed to disagree," he said. "For all other topics in ethics this didn't block very good cooperation."

But writing in Healthy Debate, Dr. Lawrence Loh, an adjunct professor at the Dalla Lama School of Public Health in Toronto and former deputy chair of the World Medical Association Junior Doctors Network, said that CMA delegates to the WMA have faced personal attacks, and that disputes over euthanasia had thwarted the CMA's attempts to serve in WMA leadership. The CMA and the Dutch medical association had intended to introduce a motion at the WMA meeting that would have changed the WMA policy to be neutral on the issue, but when it became clear that there was not enough support from other countries, the motion was dropped.
"Many feel the CMA felt snubbed and used plagiarism as a way out, as they had been threatening for three years," said Dr. Kulvinder Gill, president of the advocacy group Concerned Ontario Doctors.

In a statement, CMA president Dr. Gigi Osler repeated that the CMA's resignation was prompted by the plagiarism issue. "The Canadian Medical Association's decision to withdraw membership from the World Medical Association was the result of a very serious ethical breach at the WMA. Plagiarism is never acceptable and medical leaders should always be expected to uphold the highest standards of ethics and professionalism. For these reasons, the senior elected leaders of the CMA in attendance at the WMA meeting took a firm stand," she said.

According to Loh, in making the resignation about plagiarism only, the CMA missed an opportunity to draw attention to other ethical and governance challenges at WMA.

Gill said her group is particularly concerned that CMA members were not involved in the decision to resign from the WMA. "There was no consultation with CMA members on the resignation of Canada from an organization that Canada helped to found, and in which we have played an instrumental role for the past 71 years," she said. The group worries that the resignation leaves Canada's 85000 doctors, and the CMA, without international ethical oversight. The group is urging its members to resign from the CMA and join WMA as associate members.

Osler said the CMA is seeking other opportunities for international cooperation. "The work of the WMA is not the only opportunity for CMA to have a significant impact on the global stage. Each day, we witness Canadian physicians contributing personally to improving health and health care in countries around the world. This is one of the many reasons why we are currently seeking input from CMA members on the next chapter of our international work," she said.

The WMA is "really very unhappy" about the resignation, said Kloiber. "The CMA has been very active and productive in the WMA. I hope that at some point the Canadians will rejoin."

Brian Owens, St. Stephen, NB 